\title{
New application of anti-TLR monoclonal antibodies: detection, inhibition and protection
}

\author{
Ryutaro Fukui ${ }^{1 *}$, Yusuke Murakami ${ }^{1,2}$ and Kensuke Miyake ${ }^{1,3^{*}}$
}

\begin{abstract}
Monoclonal antibody (mAb) is an essential tool for the analysis in various fields of biology. In the field of innate immunology, mAbs have been established and used for the study of Toll-like receptors (TLRs), a family of pathogen sensors that induces cytokine production and activate immune responses. TLRs play the role as a frontline of protection against pathogens, whereas excessive activation of TLRs has been implicated in a variety of infectious diseases and inflammatory diseases. For example, TLR7 and TLR9 sense not only pathogen-derived nucleic acids, but also self-derived nucleic acids in noninfectious inflammatory diseases such as systemic lupus erythematosus (SLE) or hepatitis. Consequently, it is important to clarify the molecular mechanisms of TLRs for therapeutic intervention in these diseases. For analysis of the molecular mechanisms of TLRs, mAbs to nucleic acid-sensing TLRs were developed recently. These mAbs revealed that TLR7 and TLR9 are localized also in the plasma membrane, while TLR7 and TLR9 were thought to be localized in endosomes and lysosomes. Among these mAbs, antagonistic mAbs to TLR7 or TLR9 are able to inhibit in vitro responses to synthetic ligands. Furthermore, antagonistic mAbs mitigate inflammatory disorders caused by TLR7 or TLR9 in mice. These results suggest that antagonistic mAbs to nucleic acid-sensing TLRs are a promising tool for therapeutic intervention in inflammatory disorders caused by excessive activation of nucleic acid-sensing TLRs. Here, we summarize the molecular mechanisms of TLRs and recent progresses in the trials targeting TLRs with mAbs to control inflammatory diseases.
\end{abstract}

Keywords: Toll-like receptor, Monoclonal antibody, Inhibitory antibodies, Inflammation, Autoimmune

\section{Background}

Toll-like receptors (TLRs) recognize molecular patterns of pathogens and induce immune responses to protect host from pathogens. Although TLRs play important roles in the frontline of host defense, TLRs also recognize hostderived molecular patterns as a danger signal and lead to inflammation without infection. Given that the endogenous ligands of TLRs can be considered as metabolites, TLR responses to endogenous metabolites are likely to be under the homeostatic control [1]. Dysregulation of the interaction between TLRs and endogenous metabolites is thought to drive inflammation in a variety of diseases such as autoimmune diseases, metabolic syndrome, and heart failure. Consequently, it is important to ask whether TLRs are targets for therapeutic intervention in these diseases.

To investigate the role of TLRs in a variety of diseases, mAbs to TLRs are of great importance. For example, the mAb to mouse TLR3, 7, and 9 have shown that endogenous these TLRs are expressed on the cell surface as well as in intracellular compartments. Furthermore, several mAbs to TLRs are able to intervene TLR responses. An anti-TLR7 $\mathrm{mAb}$ is able to inhibit TLR7 responses in vitro and mitigate TLR7-dependent inflammation in vivo [2, 3]. In this review, we describe the molecular mechanisms by which TLRs drive disease progression and our trials to control TLRdependent inflammatory disorders by anti-TLR mAbs.

\footnotetext{
* Correspondence: ryu-chan@ims.u-tokyo.ac.jp

${ }^{1}$ Division of Innate Immunity, Department of Microbiology and Immunology,

The University of Tokyo, 4-6-1 Shirokanedai, Minato-ku, Tokyo 108-8639,

Japan

Full list of author information is available at the end of the article
}

\section{Overview of the molecular mechanisms of toll-like receptors \\ Toll-like receptors (TLRs) are a family of innate immune sensors, recognizing pathogen-associated molecular}


patterns (PAMPs) to activate immune response as a frontline of immune system [4-7]. TLR was found as a mammalian homolog of TOLL, the dorsoventral regulatory molecule of drosophila $[8,9]$. The number of TLR varies with each species, for example, 10 TLRs are expressed in human whereas 12 TLRs are encoded in mice. Each TLR recognizes distinct PAMPs on the cell membrane of immune cells, and classified into two groups, depending on their ligands and cellular distribution. The cell surface TLRs, consisting of TLR1, TLR2, TLR4/MD-2, TLR5, and TLR6, recognize lipid or protein derived from bacteria (Fig. 1). The other group, consisting of TLR3, TLR7, TLR8, TLR9, and TLR13, respond to nucleic acids in endolysosome (Fig. 1).

All TLRs are categorized in type I transmembrane protein. TLRs recognize the ligands at the extracellular domain consisting of multiple leucine rich repeats to activate downstream signaling pathway via intracellular C-terminal region called Toll/interleukin-1 receptor (TIR) domain [10]. After the recognition of ligand, the conformation of TLR is changed and adapter proteins are recruited to the TIR domain [11-16]. Adapter proteins initiate the signal cascade to activate nuclear factor-kappa B (NF-kB) or interferonregulatory factor (IRF), which promotes transcription of mRNA encoding cytokines/interferons [17-20].

\section{PAMPs and DAMPs, recognized by TLRs}

Although the main role for TLRs is the recognition of PAMPs to protect host from pathogens, TLRs also recognize host-derived molecules $[21,22]$. These molecules are called damage/danger-associated molecular patterns (DAMPs), released from damaged or dead cells. DAMPs are recognized by innate immune sensors and induce inflammation to facilitate the clearance of damaged cells by phagocytes [23]. If the damage is not restored, DAMPs are continuously released and recognized by innate immune sensors. The cells expressing innate immune sensors strongly produce inflammatory cytokines, and the cytokines increase tissue damages, which in turn promote release of more DAMPs, and finally, a vicious circle is constructed among DAMPs, innate immune sensors and inflammation.

DAMPs are recognized by innate immune sensors because of the similarity of the structure to PAMPs. Recently, many types of DAMPs are found as endogenous ligands of TLRs [24, 25]. For example, TLR4/MD-2 recognizes bacteria-derived lipopolysaccharide (LPS) and host-derived fatty acids as PAMPs and DAMPs, respectively [26-28]. It is well known that fatty acid is a mediator of metabolic syndrome, and obesity is a condition where the response of TLR4/MD-2 is out of control. In obese adipose tissues, production of chemokines, such as monocyte chemoattractant protein-1 (MCP-1) is enhanced, and macrophages with $\mathrm{C}-\mathrm{C}$ chemokine receptor type 2 (CCR2), the receptor of MCP-1, infiltrate into adipose tissues [29-31]. Infiltrated macrophages closely interact to adipocytes and strongly recognize saturated fatty acids released from adipocytes. As result, large amounts of cytokines are released from macrophages and vicious circle of inflammation is constructed by obesity.

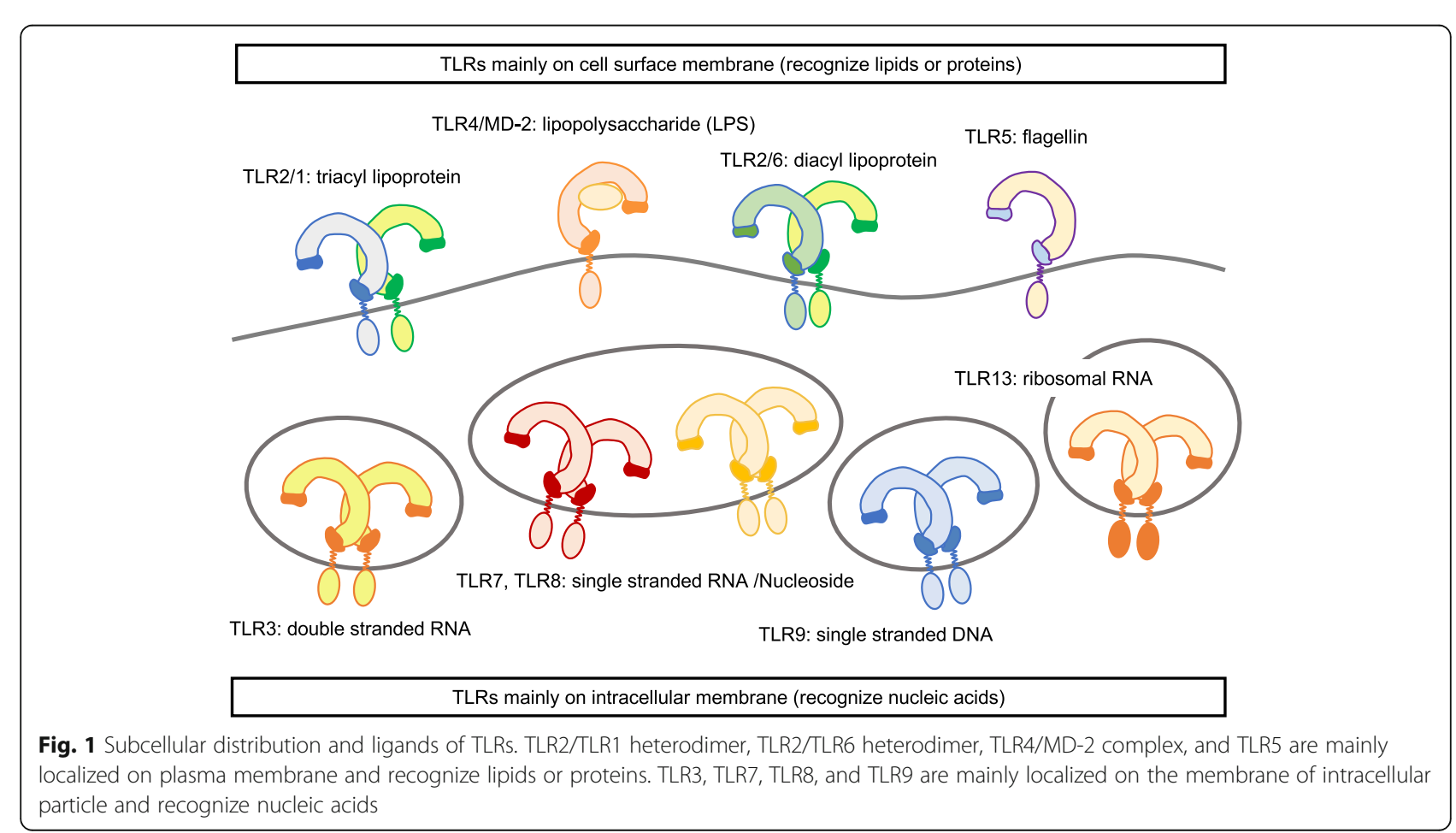


DAMPs induce inflammation and diseases, but given that DAMPs are generated and released by metabolism, inflammation induced by DAMPs is a homeostatic responses. Excessive activation of innate immune sensors by DAMPs induces chronic inflammation and irreversible tissue damage. This concept is proposed as "homeostatic inflammation" [1,32].

\section{Controlling system of toll-like receptors}

To avoid excessive homeostatic inflammation, there are multiple controlling systems for TLRs varying from gene transcription to protein degradation (Fig. 2). Especially, the responses of nucleic acid-sensing TLRs should be strictly controlled because the structure of nucleic acid is highly conserved between pathogens and hosts. TLR7, recognizing single-stranded RNA and guanosine analogs, is one of the well-known pathogenic factors of autoimmune disease model. For example, systemic lupus erythematosus (SLE)like phenotype is spontaneously induced in $\mathrm{BXSB}^{\mathrm{Yaa}}$ mice, which harbor an additional copy of the $T l r 7$ gene on $\mathrm{Y}$ chromosome (Table 1) [33-35]. Tlr7 is originally encoded on the $\mathrm{X}$ chromosome, so that $\mathrm{BXSB}^{\mathrm{Yaa}}$ mice express 2 copies of TLR7 and the response to endogenous TLR7 ligand is enhanced.

Not only the amount of TLR7, the controlling molecules of TLR7 is also important to avoid lethal inflammation [36]. Unc93 homolog B1 (UNC93B1) is one of the essential molecules for the function of nucleic acid-sensing TLRs. Furthermore, UNC93B1 balances the responses of nucleic acid-sensing TLRs [37]. UNC93B1 binds to TLRs in the ER and transport them to endolysosome where TLRs are matured by the proteolytic cleavage of the extracellular domain [38-40]. These function of UNC93B1 is abolished by the deletion or mutation of C-terminal region, while the deletion or mutation of $\mathrm{N}$-terminal region collapse the balance of the responses between TLR7 and TLR9 [37, 41, 42]. In detail, the region around 34th aspartic acid (D34) is responsible for the regulation of the

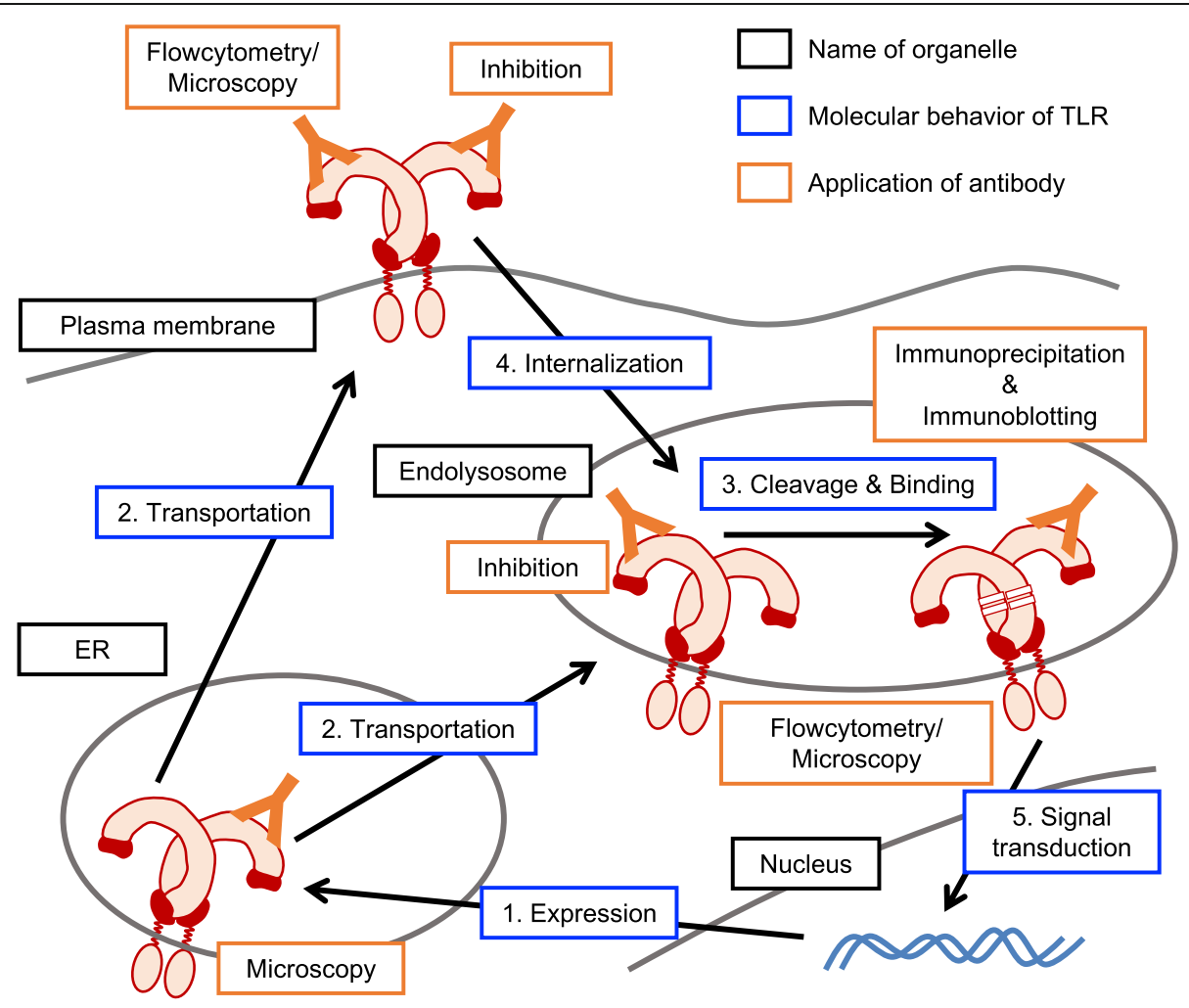

Fig. 2 Application of anti-TLR for the analysis of molecular mechanisms of TLR. Expressed TLRs are transported from ER to plasma membrane or endolysosome (1 and 2). In endolysosome, nucleic acid-sensing TLRs are cleaved and the N-terminal fragment binds to the C-terminal fragment (3). After the modification, TLR recognize ligand and signaling pathway is activated (5). TLRs on cell surface recognize ligand and activates signaling pathway. Some of them are internalized by the recognition of ligand or spontaneous trafficking (4). For the analysis of these molecular behaviors of TLR, monoclonal anti-TLR is well exploited. Amount and expression pattern among cell types are analyzed by flowcytometry. Subcellular distribution is observed by immunofluorescence microscopy. Alternatively, flowcytometry following the immunostaining with or without detergent is able to discriminate the distribution between cell surface and intracellular particle. Proteolytic cleavage and binding of nucleic acid-sensing TLR are detected by immunoprecipitation and immunoblotting. In addition to these application for detection, several antibodies have inhibitory effect on the response of TLRs. Words in black frames, blue frames, and orange frames are the name of organelle, the molecular behavior of TLR, and the application of anti-TLR, respectively 
Table 1 Relation of TLRs with chronic inflammatory diseases

\begin{tabular}{lll}
\hline Disease & TLR & Roles for TLR on disease \\
\hline Nonalcoholic & TLR4 & TLR4 mRNA expression is increased in the liver of NASH patients [49]. TLR9 recognizes host-derived mitochondrial \\
steatohepatitis (NASH) & TLR9 & DNA and induces inflammation [47, 48]. \\
Psoriasis & TLR7 & Antimicrobial peptide LL37, a factor of psoriasis, associates with self-derived DNA and stimulate TLR9 in pDCs [67]. \\
& TLR9 & Administration of imiquimod, a TLR7 ligand, induces psoriasis-like dermatitis via T cell activation with IL-17/IL-23 \\
& production [71]. \\
Systemic lupus & TLR7 & TLR7 and TLR9 contribute to the production of autoantibody in SLE model mouse [34, 35, 72]. Especially, TLR7 is \\
erythematosus (SLE) & TLR9 & thought as an inducer of the phenotype [34, 35, 73, 74]. Controversially, protective effect of TLR9 on SLE is also \\
& reported [73, 75, 76]. \\
Celiac Disease & TLR7 & Suggestive association of the SNP on TLR7 and TLR8 with celiac disease is found by genome-wide association \\
& TLR8 & study (GWAS) [77]. \\
Type 1 diabetes (T1D) & TLR4 & TLR4 expresses on $\beta$ cells in islets and induces signaling by recognizing HMGB1 [78]. TLR9 contributes to the \\
& TLR9 & activation of T cells in NOD mice, a model of T1D [69, 79, 80]. \\
Rheumatoid arthritis & TLR8 & Human TLR8 transgenic mice develop arthritis spontaneously [81]. Cathepsin K is required for the response of \\
& TLR9 & TLR9, and an inhibitor of Cathepsin K attenuates TH17 polarization and arthritis [68]. \\
\hline
\end{tabular}

responses of TLR7 and TLR9, so that the alanine mutation of the D34 (D34A mutation) enhances the response of TLR7 and declines the response of TLR9. The mice harboring D34A mutation on Unc93b1 (D34A mice) suffer from systemic inflammation, such as hepatitis, thrombocytopenia, splenomegaly and nephritis, depending on the excessive response of TLR7 [43, 44].

These TLR7-dependent disease models might develop inflammation by recognizing endogenous TLR7 ligand, such as single-stranded RNA and guanosine analogs [45, 46]. Like TLR7, TLR9 recognizes endogenous DNA ligand and also contributes to the inflammatory disease (Table 1). TLR9 recognizes mitochondrial DNA (mtDNA) released from hepatocyte and drives nonalcoholic steatohepatitis (NASH) $[47,48]$. NASH is a common liver diseases characterized by fatty liver, in which TLR9 plays a pathogenic role in driving inflammatory response by responding to mtDNA released from damaged hepatocytes [49].

\section{Anti-TLR mAbs for the analysis of molecular mechanisms in TLRs}

Given that TLRs contribute to the homeostatic inflammation and diseases, analysis of the molecular mechanisms of TLR is very important to develop therapeutic strategy. Monoclonal anti-TLRs have been established to detect endogenous TLRs from the early years of TLR research and many of new findings were brought. We also exploited mAbs for the studies of TLRs by establishing anti-murine TLR1, TLR2, TLR3, TLR4/MD-2, TLR5, TLR6, TLR7 and TLR9 (Table 2 and Fig. 2) [3, 50-54]. For example, antiTLR4/MD-2 complex monoclonal antibody reveals the direct binding of LPS to TLR4/MD-2, which is confirmed by the analysis of crystal structure later [55-57].

Anti-TLR mAbs also reveal the subcellular distribution of TLRs. As shown in Fig. 1, it was believed that TLR1, TLR2, TLR4/MD-2, and TLR6 are localized on cell surface, and TLR3, TLR7, and TLR9 are localized on intracellular vesicles. It is true and important for TLRs to be functional, but endogenous intracellular TLR1, TLR2, TLR4/-MD-2 and TLR6 were detected by flowcytometry analysis with mAbs $[50,58,59]$, and intracellular nucleic acid-sensing TLRs were detected on plasma membrane [2, 52, 53, 60].

Another important application of $\mathrm{mAb}$ is immunoprecipitation for immunoblotting. Concentration by immunoprecipitation is required for detection of endogenous TLR because the amount of endogenous TLR is not enough to detect by the immunoblotting of whole cell lysate. Even if TLRs are overexpressed, non-tagged TLR or the fragments of TLR generated by proteolytic cleavage is detectable by anti-TLR mAbs. We found that TLR9 is cleaved in endolysosome and separated to Nterminal and C-terminal fragments by using anti-TLR9 $\mathrm{mAb}$ [53]. Previous reports suggested that the cleaved C-terminal region of TLR9 is functional with the cleaved $\mathrm{N}$-terminal region serving as a negative regulator [61, 62]. We established two types of anti-TLR9 mAbs to

Table 2 Application of anti-monoclonal antibodies we established

\begin{tabular}{llll}
\hline TLR (mouse) & Name of clone & Application & Reference \\
\hline TLR1 & TR23 & FC, IP & {$[50]$} \\
TLR2 & CB225 & FC, IP & {$[50]$} \\
TLR4/MD-2 & MTS510 & FC, IP, BL (in vitro) & {$[54,57,64]$} \\
& Sa15-21 & FC, IP, BL (in vivo) & \\
TLR6 & C1N2 & FC, IP & {$[50]$} \\
TLR5 & ACT5 & FC, IP & {$[51,82]$} \\
TLR3 & CaT3 & FC, IP & {$[52]$} \\
& PaT3 & FC, IP & \\
TLR7 & A94B10 & FC, IP, IF, BL & {$[2,3,43]$} \\
TLR9 & J15A7 & FC, IP, IF & {$[53,66]$} \\
& B33A4 & FC, IP & \\
& C34A1 & FC, IP, IF & \\
& NaR9 & FC, IP, IF, BL & \\
\hline
\end{tabular}

FC flowcytometry, IP immunoprecipitation, IF immunofluorescence microscopy, $B L$ blocking 
detect the both of fragments of TLR9; one clone is bound to $\mathrm{N}$-terminal region and the other is bound to $\mathrm{C}$-terminal region [53]. By using these mAbs, we clarified that the $\mathrm{N}$ terminal region of TLR9 binds to the C-terminal region, and the binding is essential for the response of TLR9. Not only TLR9, the requirement of proteolytic cleavage and the binding of the fragments are also confirmed in TLR3 and TLR7 with monoclonal antibodies $[3,52,63]$.

\section{Inhibitory effect of anti-TLR mAbs}

Among anti-TLR mAbs, several clones inhibit the response of cells to TLR ligand. For examples, mAbs to human TLR3 (clone TLR3.7), mouse TLR4/MD-2 (clone MTS510), mouse TLR7 (clone A94B10), and mouse TLR9 (clone NaR9) inhibit the response of target TLR $[2,43,64,65]$. Interestingly, the responses of intracellular TLRs, such as TLR3, TLR7 and TLR9, are inhibited by the monoclonal antibody in culture medium. Although these TLRs are also localized on cell surface as described above, they recognize and signal nucleic acids in endolysosome. How do these inhibitory anti-TLR mAbs reach to intracellular TLRs?

In case of TLR7, a monoclonal anti-TLR7 "A94B10" binds to cell surface TLR7 and accumulated in endolysosomes as immune complex [2]. A part of the antibody uptake depends on Fc receptor, but the uptake of A94B10 remains without $F_{C}$ receptor. Furthermore, the uptake of A94B10 by the cells from $T l r 7^{-1}$ mice or UNC93B1 deficient mice is attenuated. Since UNC93B1 is essential for the cell surface localization of TLR7, inhibitory function of A94B10 might depend on cell surface TLR7.

A monoclonal anti-TLR9, clone "NaR9" also inhibits TLR9 responses. A94B10 inhibits the response of TLR7 in various types of cells, such as bone marrow-derived macrophages (BM-MCs), BM-conventional dendritic cells (BM-cDCs), BM-plasmacytoid DCs (BM-pDCs), and B cells, whereas NaR9 only inhibits the response of TLR9 in BM-MCs and BM-cDCs [66]. As a mechanism behind the difference between these two mAbs remains unclarified, NaR9 is internalized by BM-MCs and BM-cDCs but not by pDCs. Interaction between $\mathrm{mAb}$ and cell surface TLR7 or TLR9 and subsequent internalization are likely to be required for the inhibitory effect of these mAbs.

\section{New application of anti-TLR mAbs for therapeutic intervention}

If an inhibitory anti-TLR mAb is functional in vivo, the antibody is able to be applied to the treatment of inflammatory diseases induced by TLRs (Table 1). Among the antibodies mentioned above, an anti-TLR9 NaR9 rescues the mice from TLR9-dependent lethal experimental hepatitis [66]. Although the effect of NaR9 on the chronic inflammatory disease is unknown, pre-treatment of NaR9 significantly reduce the inflammatory cytokine production and acute hepatitis induced by $\mathrm{D}-(+)$-galactosamine and TLR9 ligand CpG-ODN. These results suggest that NaR9 is able to inhibit TLR9-dependent hepatitis. As TLR9 is suggested to drive inflammation in NASH, anti-TLR9 $\mathrm{mAb}$ may be promising for therapeutic intervention in $\mathrm{NASH}$ or other diseases such as psoriasis, rheumatoid arthritis, and type 1 diabetes (Table 1) [47, 67-69].

Anti-TLR4/MD-2 monoclonal antibody, Sa15-21 also rescues the mice from lethal experimental hepatitis induced by $\mathrm{D}-(+)$-galactosamine and TLR4 ligand LPS [64]. Interestingly, Sa15-21 does not directly inhibit the response of TLR4/MD-2, on contrary, enhances the response of TLR4/MD-2 and increase the production of TNF- $\alpha$. In fact, Sa15-21 induces antiapoptotic genes via TLR4/MD-2 with agonistic effect and protects mice from lethal hepatitis.

For the treatment of inflammatory disease, an inhibitory anti-TLR7 monoclonal antibody, clone A94B10 is effective in the systemic inflammation caused by TLR7 hyperresponse [2]. As mentioned above, the mice harboring the D34A mutation on UNC93B1 (D34A mice) suffer from severe inflammation with TLR7-dependent manner. The administration of A94B10 to D34A mice significantly attenuates the phenotypes, such as splenomegaly, thrombocytopenia, autoantibody production, and hepatitis with fibrosis of liver. It is important to distinguish whether the effect of antibody is therapeutic or prophylactic. Even if the administration of A94B10 was started when D34A mice had already developed thrombocytopenia, the antiTLR7 mAb was still effective. These results suggest that anti-TLR7 is a promising candidate of therapeutic drug to cure TLR7-dependent autoimmune diseases, for examples, SLE or autoimmune hepatitis.

\section{Conclusion}

Homeostatic inflammation induced by TLRs is tightly related to health and disease. To investigate the molecular mechanisms of TLRs, monoclonal antibody is an essential tool for experiment. In these 2 decades, many researchers have revealed a variety of the molecular properties of TLRs with anti-TLR monoclonal antibodies. Moreover, the application of anti-TLR monoclonal antibody is expanding to therapeutic intervention. There is no evidence of the therapeutic effect of anti-TLR on the disease in human, however, TLR antagonist nucleic acids has already proceeded to clinical trial [70]. If the trial of nucleic acid medicine is successful, development of anti-human TLR mAbs will also be a promising way to control TLR-dependent diseases. Of course, the application of anti-TLR mAbs might compete nucleic acid medicine, but $m A$ bs have advantages of higher specificity, lower off-target effect, and longer half-life comparing to nucleic acids. Not only for clinical application, anti-human TLR should be continuously established for the analysis of the molecular mechanism of human TLRs. 


\section{Abbreviations}

BM-CDC: bone marrow-derived conventional dendritic cell; BM-MC: bone marrow-derived macrophage; BM-pDC: bone marrow-derived plasmacytoid dendritic cell; CCR2: C-C chemokine receptor type 2; D34A mutation: alanine mutant of 34th aspartic acid in UNC93B1; DAMPs: damage/danger-associated molecular patterns; IRF: interferon-regulatory factor; mAb: monoclonal antibody; MCP-1: monocyte chemoattractant protein-1; mtDNA: mitochondrial DNA; NASH: nonalcoholic steatohepatitis; NF-kB: nuclear factor-kappa B; PAMPs: pathogen-associated molecular patterns; SLE: systemic lupus erythematosus; TIR domain: Toll/IL-1 receptor domain; TLR: Toll-like receptor; UNC93B1: Unc93 homolog B1

\section{Funding}

This work was supported in part by a contract research fund from JSPS for Grant-in-Aid for Scientific Research (S), 16H06388; Grant-in-Aid for Exploratory Research, 17 K19548; from Takeda Science Foundation; from SENSHIN Medical Research Foundation.

\section{Authors' contributions}

RF wrote the manuscript. YM and KM revised manuscript. All authors read and approved the manuscript.

\section{Ethics approval and consent to participate}

Not applicable.

\section{Competing interests}

The authors declare that they have no competing interests.

\section{Publisher's Note}

Springer Nature remains neutral with regard to jurisdictional claims in published maps and institutional affiliations.

\section{Author details}

${ }^{1}$ Division of Innate Immunity, Department of Microbiology and Immunology, The University of Tokyo, 4-6-1 Shirokanedai, Minato-ku, Tokyo 108-8639, Japan. ${ }^{2}$ Department of Pharmacotherapy, Research Institute of Pharmaceutical Sciences, Musashino University, 1-1-20 Shin-machi, Nishitokyo-shi, Tokyo 202-8585, Japan. ${ }^{3}$ Laboratory of Innate Immunity, Center for Experimental Medicine and Systems Biology, The Institute of Medical Science, The University of Tokyo, 4-6-1 Shirokanedai, Minato-ku, Tokyo 108-8639, Japan.

Received: 6 February 2018 Accepted: 19 April 2018

Published online: 03 July 2018

\section{References}

1. Miyake K, Kaisho T. Homeostatic inflammation in innate immunity. Curr Opin Immunol. 2014;30C:85-90.

2. Kanno A, Tanimura N, Ishizaki M, Ohko K, Motoi Y, Onji M, Fukui R, Shimozato T, Yamamoto K, Shibata T, et al. Targeting cell surface TLR7 for therapeutic intervention in autoimmune diseases. Nat Commun. 2015;6:6119.

3. Kanno A, Yamamoto C, Onji M, Fukui R, Saitoh S, Motoi Y, Shibata T, Matsumoto F, Muta T, Miyake K. Essential role for toll-like receptor 7 (TLR7)unique cysteines in an intramolecular disulfide bond, proteolytic cleavage and RNA sensing. Int Immunol. 2013;25(7):413-22.

4. Akira $S$, Uematsu $S$, Takeuchi O. Pathogen recognition and innate immunity. Cell. 2006;124(4):783-801.

5. Takeda K, Akira S. Toll-like receptors in innate immunity. Int Immunol. 2005; 17(1):1-14.

6. Takeuchi O, Akira S. Pattern recognition receptors and inflammation. Cell. 2010;140(6):805-20.

7. Brubaker SW, Bonham KS, Zanoni I, Kagan JC. Innate immune pattern recognition: a cell biological perspective. Annu Rev Immunol. 2015;33:257-90.

8. Medzhitov R, Preston-Hurlburt P, Janeway CA Jr. A human homologue of the Drosophila toll protein signals activation of adaptive immunity. Nature. 1997:388(6640):394-7.

9. Lemaitre B, Nicolas E, Michaut L, Reichhart JM, Hoffmann JA. The dorsoventral regulatory gene cassette spatzle/toll/cactus controls the potent antifungal response in Drosophila adults. Cell. 1996;86(6):973-83.

10. Akira S, Takeda K. Toll-like receptor signalling. Nat Rev Immunol. 2004;4(7): 499-511.
11. Yamamoto M, Sato S, Hemmi H, Hoshino K, Kaisho T, Sanjo H, Takeuchi O, Sugiyama M, Okabe M, Takeda K, et al. Role of adaptor TRIF in the MyD88independent toll-like receptor signaling pathway. Science. 2003;301(5633):640-3.

12. Yamamoto M, Sato S, Hemmi H, Sanjo H, Uematsu S, Kaisho T, Hoshino K, Takeuchi O, Kobayashi M, Fujita T, et al. Essential role for TIRAP in activation of the signalling cascade shared by TLR2 and TLR4. Nature. 2002:420(6913):324-9.

13. Yamamoto M, Sato S, Hemmi H, Uematsu S, Hoshino K, Kaisho T, Takeuchi O, Takeda K, Akira S. TRAM is specifically involved in the toll-like receptor 4-mediated MyD88-independent signaling pathway. Nat Immunol. 2003;4(11):1144-50.

14. Takeuchi O, Takeda K, Hoshino K, Adachi O, Ogawa T, Akira S. Cellular responses to bacterial cell wall components are mediated through MyD88dependent signaling cascades. Int Immunol. 2000;12(1):113-7.

15. Oshiumi H, Matsumoto M, Funami K, Akazawa T, Seya T. TICAM-1, an adaptor molecule that participates in toll-like receptor 3-mediated interferon-beta induction. Nat Immunol. 2003:4(2):161-7.

16. Oshiumi H, Sasai M, Shida K, Fujita T, Matsumoto M, Seya T. TIR-containing adapter molecule (TICAM)-2, a bridging adapter recruiting to toll-like receptor 4 TICAM-1 that induces interferon-beta. J Biol Chem. 2003;278(50): 49751-62.

17. Zhang G, Ghosh S. Toll-like receptor-mediated NF-kappaB activation: a phylogenetically conserved paradigm in innate immunity. J Clin Invest. 2001;107(1):13-9.

18. Kawai T, Akira S. Signaling to NF-kappaB by toll-like receptors. Trends Mol Med. 2007;13(11):460-9.

19. Schoenemeyer A, Barnes BJ, Mancl ME, Latz E, Goutagny N, Pitha PM, Fitzgerald KA, Golenbock DT. The interferon regulatory factor, IRF5, is a central mediator of toll-like receptor 7 signaling. J Biol Chem. 2005;280(17): 17005-12.

20. Fitzgerald KA, Rowe DC, Barnes BJ, Caffrey DR, Visintin A, Latz E, Monks B, Pitha PM, Golenbock DT. LPS-TLR4 signaling to IRF-3/7 and NF-kappaB involves the toll adapters TRAM and TRIF. J Exp Med. 2003;198(7):1043-55.

21. Marshak-Rothstein A, Rifkin IR. Immunologically active autoantigens: the role of toll-like receptors in the development of chronic inflammatory disease. Annu Rev Immunol. 2007:25:419-41.

22. Chen GY, Nunez G. Sterile inflammation: sensing and reacting to damage. Nat Rev Immunol. 2010;10(12):826-37.

23. Schaefer L. Complexity of danger: the diverse nature of damage-associated molecular patterns. J Biol Chem. 2014;289(51):35237-45.

24. Alvarez K, Vasquez G. Damage-associated molecular patterns and their role as initiators of inflammatory and auto-immune signals in systemic lupus erythematosus. Int Rev Immunol. 2017;36(5):259-70.

25. Yu L, Wang L, Chen S. Endogenous toll-like receptor ligands and their biological significance. J Cell Mol Med. 2010;14(11):2592-603.

26. Suganami T, Mieda T, Itoh M, Shimoda Y, Kamei Y, Ogawa Y. Attenuation of obesity-induced adipose tissue inflammation in $\mathrm{C} 3 \mathrm{H} / \mathrm{HeJ}$ mice carrying a tolllike receptor 4 mutation. Biochem Biophys Res Commun. 2007;354(1):45-9.

27. Suganami T, Tanimoto-Koyama K, Nishida J, Itoh M, Yuan X, Mizuarai S, Kotani H, Yamaoka S, Miyake K, Aoe S, et al. Role of the toll-like receptor 4/ NF-kappaB pathway in saturated fatty acid-induced inflammatory changes in the interaction between adipocytes and macrophages. Arterioscler Thromb Vasc Biol. 2007;27(1):84-91.

28. Wong SW, Kwon MJ, Choi AM, Kim HP, Nakahira K, Hwang DH. Fatty acids modulate toll-like receptor 4 activation through regulation of receptor dimerization and recruitment into lipid rafts in a reactive oxygen speciesdependent manner. J Biol Chem. 2009;284(40):27384-92.

29. Ito A, Suganami T, Yamauchi A, Degawa-Yamauchi M, Tanaka M, Kouyama R, Kobayashi Y, Nitta N, Yasuda K, Hirata Y, et al. Role of CC chemokine receptor 2 in bone marrow cells in the recruitment of macrophages into obese adipose tissue. J Biol Chem. 2008;283(51):35715-23.

30. Kamei N, Tobe K, Suzuki R, Ohsugi M, Watanabe T, Kubota N, OhtsukaKowatari N, Kumagai K, Sakamoto K, Kobayashi M, et al. Overexpression of monocyte chemoattractant protein-1 in adipose tissues causes macrophage recruitment and insulin resistance. J Biol Chem. 2006;281(36):26602-14.

31. Weisberg SP, Hunter D, Huber R, Lemieux J, Slaymaker S, Vaddi K, Charo I, Leibel RL, Ferrante AW Jr. CCR2 modulates inflammatory and metabolic effects of high-fat feeding. J Clin Invest. 2006;116(1):115-24.

32. Fukui R, Miyake K. Controlling systems of nucleic acid sensing-TLRs restrict homeostatic inflammation. Exp Cell Res. 2012;318(13):1461-6.

33. Fairhurst AM, Hwang SH, Wang A, Tian XH, Boudreaux C, Zhou XJ, Casco J, Li QZ, Connolly JE, Wakeland EK. Yaa autoimmune phenotypes are conferred by overexpression of TLR7. Eur J Immunol. 2008;38(7):1971-8. 
34. Pisitkun P, Deane JA, Difilippantonio MJ, Tarasenko T, Satterthwaite AB, Bolland S. Autoreactive B cell responses to RNA-related antigens due to TLR7 gene duplication. Science. 2006;312(5780):1669-72.

35. Santiago-Raber ML, Kikuchi S, Borel P, Uematsu S, Akira S, Kotzin BL, Izui S. Evidence for genes in addition to Tlr7 in the Yaa translocation linked with acceleration of systemic lupus erythematosus. J Immunol. 2008;181(2):1556-62.

36. Lee CC, Avalos AM, Ploegh HL. Accessory molecules for toll-like receptors and their function. Nat Rev Immunol. 2012;12(3):168-79.

37. Tabeta K, Hoebe K, Janssen EM, Du X, Georgel P, Crozat K, Mudd S, Mann N, Sovath S, Goode J, et al. The Unc93b1 mutation 3d disrupts exogenous antigen presentation and signaling via toll-like receptors 3, 7 and 9. Nat Immunol. 2006;7(2):156-64.

38. Brinkmann MM, Spooner E, Hoebe K, Beutler B, Ploegh HL, Kim YM. The interaction between the ER membrane protein UNC93B and TLR3, 7, and 9 is crucial for TLR signaling. J Cell Biol. 2007:177(2):265-75.

39. Kim YM, Brinkmann MM, Paquet ME, Ploegh HL. UNC93B1 delivers nucleotide-sensing toll-like receptors to endolysosomes. Nature. 2008; 452(7184):234-8

40. Lee BL, Moon JE, Shu JH, Yuan L, Newman ZR, Schekman R, Barton GM UNC93B1 mediates differential trafficking of endosomal TLRs. elife. 2013;2: e00291.

41. Fukui R, Saitoh S, Matsumoto F, Kozuka-Hata H, Oyama M, Tabeta K, Beutler B, Miyake K. Unc93B1 biases toll-like receptor responses to nucleic acid in dendritic cells toward DNA- but against RNA-sensing. J Exp Med. 2009; 206(6):1339-50.

42. Casrouge A, Zhang SY, Eidenschenk C, Jouanguy E, Puel A, Yang K, Alcais A, Picard C, Mahfoufi N, Nicolas N, et al. Herpes simplex virus encephalitis in human UNC-93B deficiency. Science. 2006;314(5797):308-12.

43. Fukui R, Kanno A, Miyake K. Type I IFN contributes to the phenotype of Unc93b1D34A/D34A mice by regulating TLR7 expression in B cells and dendritic cells. J Immunol. 2016;196(1):416-27.

44. Fukui R, Saitoh S, Kanno A, Onji M, Shibata T, Ito A, Matsumoto M, Akira S, Yoshida N, Miyake K. Unc93B1 restricts systemic lethal inflammation by orchestrating toll-like receptor 7 and 9 trafficking. Immunity. 2011;35(1):69-81.

45. Shibata T, Ohto U, Nomura S, Kibata K, Motoi Y, Zhang Y, Murakami Y, Fukui $\mathrm{R}$, Ishimoto $\mathrm{T}$, Sano $\mathrm{S}$, et al. Guanosine and its modified derivatives are endogenous ligands for TLR7. Int Immunol. 2016;28(5):211-22.

46. Zhang Z, Ohto U, Shibata T, Krayukhina E, Taoka M, Yamauchi Y, Tanji H, Isobe T, Uchiyama S, Miyake K, et al. Structural analysis reveals that toll-like receptor 7 is a dual receptor for guanosine and single-stranded RNA. Immunity. 2016;45(4):737-48

47. Garcia-Martinez I, Santoro N, Chen Y, Hoque R, Ouyang X, Caprio S, Shlomchik MJ, Coffman RL, Candia A, Mehal WZ. Hepatocyte mitochondrial DNA drives nonalcoholic steatohepatitis by activation of TLR9. J Clin Invest. 2016;126(3):859-64.

48. Miura K, Kodama Y, Inokuchi S, Schnabl B, Aoyama T, Ohnishi H, Olefsky JM, Brenner DA, Seki E. Toll-like receptor 9 promotes steatohepatitis by induction of interleukin-1 beta in mice. Gastroenterology. 2010;139(1):323-34. e327

49. Sharifnia T, Antoun J, Verriere TG, Suarez G, Wattacheril J, Wilson KT, Peek RM Jr, Abumrad NN, Flynn CR. Hepatic TLR4 signaling in obese NAFLD. Am J Physiol Gastrointest Liver Physiol. 2015;309(4):G270-8.

50. Motoi Y, Shibata T, Takahashi K, Kanno A, Murakami Y, Li X, Kasahara T, Miyake K. Lipopeptides are signaled by toll-like receptor 1, 2 and 6 in endolysosomes. Int Immunol. 2014;26(10):563-73.

51. Shibata T, Takemura N, Motoi Y, Goto Y, Karuppuchamy T, Izawa K, Li X, Akashi-Takamura S, Tanimura N, Kunisawa J, et al. PRAT4A-dependent expression of cell surface TLR5 on neutrophils, classical monocytes and dendritic cells. Int Immunol. 2012;24(10):613-23.

52. Murakami Y, Fukui R, Motoi Y, Kanno A, Shibata T, Tanimura N, Saitoh S, Miyake K. Roles of the cleaved N-terminal TLR3 fragment and cell surface TLR3 in double-stranded RNA sensing. J Immunol. 2014;193(10): 5208-17.

53. Onji M, Kanno A, Saitoh S, Fukui R, Motoi Y, Shibata T, Matsumoto F, Lamichhane A, Sato S, Kiyono H, et al. An essential role for the N-terminal fragment of toll-like receptor 9 in DNA sensing. Nat Commun. 2013;4:1949.

54. Akashi S, Shimazu R, Ogata H, Nagai Y, Takeda K, Kimoto M, Miyake K. Cutting edge: cell surface expression and lipopolysaccharide signaling via the toll-like receptor 4-MD-2 complex on mouse peritoneal macrophages. J Immunol. 2000;164(7):3471-5.

55. Ohto U, Fukase K, Miyake K, Satow Y. Crystal structures of human MD-2 and its complex with antiendotoxic lipid IVa. Science. 2007;316(5831):1632-4
56. Park BS, Song DH, Kim HM, Choi BS, Lee H, Lee JO. The structural basis of lipopolysaccharide recognition by the TLR4-MD-2 complex. Nature. 2009; 458(7242):1191-5

57. Akashi S, Saitoh S, Wakabayashi Y, Kikuchi T, Takamura N, Nagai Y, Kusumoto Y, Fukase K, Kusumoto S, Adachi Y, et al. Lipopolysaccharide interaction with cell surface toll-like receptor 4-MD-2: higher affinity than that with MD-2 or CD14. J Exp Med. 2003;198(7):1035-42.

58. Shibata T, Motoi Y, Tanimura N, Yamakawa N, Akashi-Takamura S, Miyake K. Intracellular TLR4/MD-2 in macrophages senses gram-negative bacteria and induces a unique set of LPS-dependent genes. Int Immunol. 2011;23(8):503-10.

59. Chan MP, Onji M, Fukui R, Kawane K, Shibata T, Saitoh S, Ohto U, Shimizu T, Barber GN, Miyake K. DNase II-dependent DNA digestion is required for DNA sensing by TLR9. Nat Commun. 2015;6:5853.

60. Pohar J, Pirher N, Bencina M, Mancek-Keber M, Jerala R. The role of UNC93B1 protein in surface localization of TLR3 receptor and in cell priming to nucleic acid agonists. J Biol Chem. 2013;288(1):442-54.

61. Park B, Brinkmann MM, Spooner E, Lee CC, Kim YM, Ploegh HL. Proteolytic cleavage in an endolysosomal compartment is required for activation of toll-like receptor 9. Nat Immunol. 2008;9(12):1407-14.

62. Ewald SE, Lee BL, Lau L, Wickliffe KE, Shi GP, Chapman HA, Barton GM. The ectodomain of toll-like receptor 9 is cleaved to generate a functional receptor. Nature. 2008;456(7222):658-62.

63. Toscano F, Estornes Y, Virard F, Garcia-Cattaneo A, Pierrot A, Vanbervliet B, Bonnin M, Ciancanelli MJ, Zhang SY, Funami K, et al. Cleaved/associated TLR3 represents the primary form of the signaling receptor. J Immunol. 2013;190(2):764-73.

64. Akashi-Takamura S, Furuta T, Takahashi K, Tanimura N, Kusumoto Y, Kobayashi T, Saitoh S, Adachi Y, Doi T, Miyake K. Agonistic antibody to TLR4/MD-2 protects mice from acute lethal hepatitis induced by TNF-alpha. J Immunol. 2006;176(7):4244-51.

65. Matsumoto M, Kikkawa S, Kohase M, Miyake K, Seya T. Establishment of a monoclonal antibody against human toll-like receptor 3 that blocks doublestranded RNA-mediated signaling. Biochem Biophys Res Commun. 2002; 293(5):1364-9.

66. Murakami Y, Fukui R, Motoi Y, Shibata T, Saitoh SI, Sato R, Miyake K. The protective effect of the anti-toll-like receptor 9 antibody against acute cytokine storm caused by immunostimulatory DNA. Sci Rep. 2017;7:44042.

67. Lande R, Gregorio J, Facchinetti V, Chatterjee B, Wang YH, Homey B, Cao W, Su B, Nestle FO, Zal T, et al. Plasmacytoid dendritic cells sense self-DNA coupled with antimicrobial peptide. Nature. 2007;449(7162):564-9.

68. Asagiri M, Hirai T, Kunigami T, Kamano S, Gober HJ, Okamoto K, Nishikawa K, Latz E, Golenbock DT, Aoki K, et al. Cathepsin K-dependent toll-like receptor 9 signaling revealed in experimental arthritis. Science. 2008; 319(5863):624-7.

69. Wong FS, Hu C, Zhang L, Du W, Alexopoulou L, Flavell RA, Wen L. The role of toll-like receptors 3 and 9 in the development of autoimmune diabetes in NOD mice. Ann N Y Acad Sci. 2008;1150:146-8.

70. Balak DM, van Doorn MB, Arbeit RD, Rijneveld R, Klaassen E, Sullivan T, Brevard J, Thio HB, Prens EP, Burggraaf J, et al. IMO-8400, a toll-like receptor 7,8 , and 9 antagonist, demonstrates clinical activity in a phase $2 a$, randomized, placebo-controlled trial in patients with moderate-to-severe plaque psoriasis. Clin Immunol. 2016;174:63-72.

71. van der Fits L, Mourits S, Voerman JS, Kant M, Boon L, Laman JD, Cornelissen F, Mus AM, Florencia E, Prens EP, et al. Imiquimod-induced psoriasis-like skin inflammation in mice is mediated via the IL-23/IL-17 axis. J Immunol. 2009;182(9):5836-45.

72. Christensen SR, Kashgarian M, Alexopoulou L, Flavell RA, Akira S, Shlomchik MJ. Toll-like receptor 9 controls anti-DNA autoantibody production in murine lupus. J Exp Med. 2005;202(2):321-31.

73. Christensen SR, Shupe J, Nickerson K, Kashgarian M, Flavell RA, Shlomchik MJ. Toll-like receptor 7 and TLR9 dictate autoantibody specificity and have opposing inflammatory and regulatory roles in a murine model of lupus. Immunity. 2006;25(3):417-28.

74. Deane JA, Pisitkun P, Barrett RS, Feigenbaum L, Town T, Ward JM, Flavell RA Bolland S. Control of toll-like receptor 7 expression is essential to restrict autoimmunity and dendritic cell proliferation. Immunity. 2007;27(5):801-10.

75. Nickerson KM, Christensen SR, Cullen JL, Meng W, Luning Prak ET, Shlomchik MJ. TLR9 promotes tolerance by restricting survival of anergic anti-DNA B cells, yet is also required for their activation. J Immunol. 2013; 190(4):1447-56. 
76. Nickerson KM, Christensen SR, Shupe J, Kashgarian M, Kim D, Elkon K, Shlomchik MJ. TLR9 regulates TLR7- and MyD88-dependent autoantibody production and disease in a murine model of lupus. J Immunol. 2010;184(4):1840-8.

77. Dubois PC, Trynka G, Franke L, Hunt KA, Romanos J, Curtotti A, Zhernakova A Heap GA, Adany R, Aromaa A, et al. Multiple common variants for celiac disease influencing immune gene expression. Nat Genet. 2010;42(4):295-302.

78. Li M, Song L, Gao X, Chang W, Qin X. Toll-like receptor 4 on islet beta cells senses expression changes in high-mobility group box 1 and contributes to the initiation of type 1 diabetes. Exp Mol Med. 2012;44(4):260-7.

79. Tai $N$, Wong FS, Wen $L$. The role of the innate immune system in destruction of pancreatic beta cells in NOD mice and humans with type I diabetes. J Autoimmun. 2016;71:26-34.

80. Tai N, Wong FS, Wen L. TLR9 deficiency promotes CD73 expression in T cells and diabetes protection in nonobese diabetic mice. J Immunol. 2013; 191(6):2926-37.

81. Guiducci C, Gong M, Cepika AM, Xu Z, Tripodo C, Bennett L, Crain C, Quartier P, Cush JJ, Pascual V, et al. RNA recognition by human TLR8 can lead to autoimmune inflammation. J Exp Med. 2013;210(13):2903-19.

82. Huh JW, Shibata T, Hwang M, Kwon EH, Jang MS, Fukui R, Kanno A, Jung DJ, Jang MH, Miyake K, et al. UNC93B1 is essential for the plasma membrane localization and signaling of toll-like receptor 5. Proc Natl Acad Sci U S A. 2014;111(19):7072-7.

Ready to submit your research? Choose BMC and benefit from:

- fast, convenient online submission

- thorough peer review by experienced researchers in your field

- rapid publication on acceptance

- support for research data, including large and complex data types

- gold Open Access which fosters wider collaboration and increased citations

- maximum visibility for your research: over $100 \mathrm{M}$ website views per year

At BMC, research is always in progress.

Learn more biomedcentral.com/submissions 